\title{
ИНДИВИДУАЛЬНАЯ ПРЕДРАСПОЛОЖЕННОСТЬ К ДЕЙСТВИЮ ПРОИЗВОДСТВЕННО- ЭКОЛОГИЧЕСКИХ БИОЛОГИЧЕСКИХ ФАКТОРОВ У ГОРНОРАБОЧИХ ПО АЛЛОАНТИГЕННЫМ ТКАНЕВЫМ СТРУКТУРАМ
}

\author{
${ }^{1}$ Чергизова Б.Т., ${ }^{2}$ Шарипова П.А., ${ }^{3}$ \\ Атаходжаева М.А., ${ }^{4}$ Ииигов И.А., ${ }^{5}$ Иманова Д.Н. \\ НАО Карагандинский медииинский университет \\ Ташкентский государственный медицинский стоматологический институт \\ Международный казахско-туреикий университет им.Х.А.Ясави
}

\begin{abstract}
Аннотация. В данной статье дается сравнительный анализ индивидуальных различий в развитии профессиональных заболеваний, в основе которых лежит генетический полиморфизм человека. В формировании хронических заболеваний у горнорабочих добывающей промышленности, подвергающихся комплексному воздействию вредных производственных факторов, принимают участие генетические системы организма и определяют индивидуальную чувствительность в патогенным агентам. Изучение генетических маркеров позволяет обосновать критерии профессионального отбора и провести более эффективные профилактические мероприятия.

Abstract. This article provides a comparative analysis of individual differences in the development of occupational diseases, which are based on human genetic polymorphism. The genetic systems of the body take part in the formation of chronic diseases in mining workers exposed to the complex effects of harmful production factors and determine individual sensitivity to pathogenic agents. The study of genetic markers allows us to justify the criteria for professional selection and to conduct more effective preventive measures.

Ключевые слова: маркеры, группы крови, система АВО, антигенны, фенотипы, бронхолегочные заболевания, стаж работы.

Key words: markers, blood groups, $\mathrm{ABO}$ system, antigens, phenotypes, bronchopulmonary diseases, work experience.
\end{abstract}

Данные о потенциальном воздействии средовых загрязнителей на наследственность человека и их способность нарушать функцию репродуктивной системы вызывают глобальную озабоченность. В условиях Центрального Казахстана особое значение имеет пылевая нагрузка на население, т.к. среди всех антропогенных факторов пыль занимает одно из приоритетных положений по количеству выбросов [1].

В формировании хронических заболеваний у рабочих, подвергающихся воздействию вредных производственных факторов, принимают участие генетические системы организма, контролирующие его разнообразные функции и определяющие индивидуальную чувствительность к патогенным агентам [2].

Цель: В настоящее время имеет интерес вопрос о связи фенотипических характеристик групп крови с предрасположенностью к бронхолегочным заболеваниям, закономерностям распределения фенотипов групп крови в зависимости от формы легочной патологии, рассмотрение генетического полиморфизма эритроцитарных аллоантигенов $\mathrm{ABO}$ и резус-фактора $(\mathrm{Rh})$.

Материалы и методы: проведено исследование 115 горнорабочих рудника по добыче вольфраммолибденсодержащей руды: 1 группа - 57 больных с хроническим пылевым бронхитом (ХПБ), 2 группа - 30 больных с пневмокониозами (Пн) и 3 группа - 28 больных с бронхиальной астмой (БА).

Результаты исследования: На основе анализа установлены статистически достоверные различия в распределении генетических факторов по группам крови $\mathrm{ABO}$ и резус-фактору (таблица 1).

Распределение больных по фенотипам группы крови АВО

\begin{tabular}{|c|c|c|c|c|c|c|}
\hline $\begin{array}{c}\text { Фенотип } \\
\text { группы } \\
\text { крови }\end{array}$ & $\begin{array}{c}1 \text { группа - Хронический пылевой } \\
\text { бронхит (ХПБ) }\end{array}$ & $\begin{array}{c}2 \text { группа- Пневмокониозы } \\
\text { (Пн) }\end{array}$ & \multicolumn{2}{c|}{$\begin{array}{c}3 \text { группа-Бронхиальная } \\
\text { астма (БА) }\end{array}$} \\
\cline { 2 - 7 } & $\mathrm{n}$ & $\%$ & $\mathrm{n}$ & $\%$ & $\mathrm{n}$ & $\%$ \\
\hline $\mathrm{O}$ & 16 & 28,1 & 9 & 30,0 & 10 & 35,7 \\
\hline $\mathrm{A}$ & 25 & 43,8 & 12 & 40,0 & 7 & 25,0 \\
\hline $\mathrm{B}$ & 13 & 22,8 & 7 & 23,3 & 11 & 39,3 \\
\hline $\mathrm{AB}$ & 3 & 5,3 & 2 & 6,7 & - & - \\
\hline Всего & 57 & 100 & 30 & 100 & 28 & 100 \\
\hline
\end{tabular}

В результате распределения и анализа генетических факторов по группам крови выявлен достоверный статистический рост фенотипа А у больных с хроническим пылевым бронхитом и пневмокониозами, аналогично фенотип О встречался в равной степени в 1 и 2 группе - 28,1\% и $30 \%$. В 3-й группе фенотип АВ встречается в большей степени, чем фенотип О и $\mathrm{A}$, интересен тот факт, что аллоантиген $\mathrm{AB}$ не выявлен вообще у больных с 
бронхиальной астмой. Распределение обследованных по выявлению положительного антигена фенотипа (Rh+) наблюдается выраженный характер во всех группах по сравнению с отрицательным резус-фактором (таблица 2).

Распределение обследованных по резус-фактору

\begin{tabular}{|c|c|c|c|c|c|c|}
\hline \multirow{2}{*}{ Фенотип резус-фактора } & \multicolumn{2}{|c|}{1 групп - ХПБ } & \multicolumn{2}{|c|}{$\begin{array}{c}2 \text { группа- Пневмокониозы } \\
\text { (Пн) }\end{array}$} & \multicolumn{2}{c|}{$\begin{array}{c}\text { группа-Бронхиальная } \\
\text { астма (БА) }\end{array}$} \\
\cline { 2 - 7 } & $\mathrm{n}$ & $\%$ & $\mathrm{n}$ & $\%$ & $\mathrm{n}$ & $\%$ \\
\hline $\mathrm{Rh}+$ & 48 & 84,2 & 26 & 86,7 & 17 & 60,7 \\
\hline Rh- & 9 & 15,8 & 4 & 13,3 & 11 & 39,3 \\
\hline Всего & 57 & 100 & 30 & 100 & 28 & 100 \\
\hline
\end{tabular}

Частота изучаемых фенотипов группы крови АВО при распределении по стажу до 20 лет в 1 -й группе с ХПБ было $27,5 \%$, во 2 -й группе с Пн 14,5\% и в 3 группе с бронхиальной астмой $13,5 \%$, у рабочих со стажем более 20 лет преобладали больные с пневмокониозом и хроническим пылевым бронхитом $-73 \%$ и $72 \%$ соответственно и $57 \%$ было с бронхиальной астмой, данные показатели в сравнении представлены в диаграмме 1 и 2.

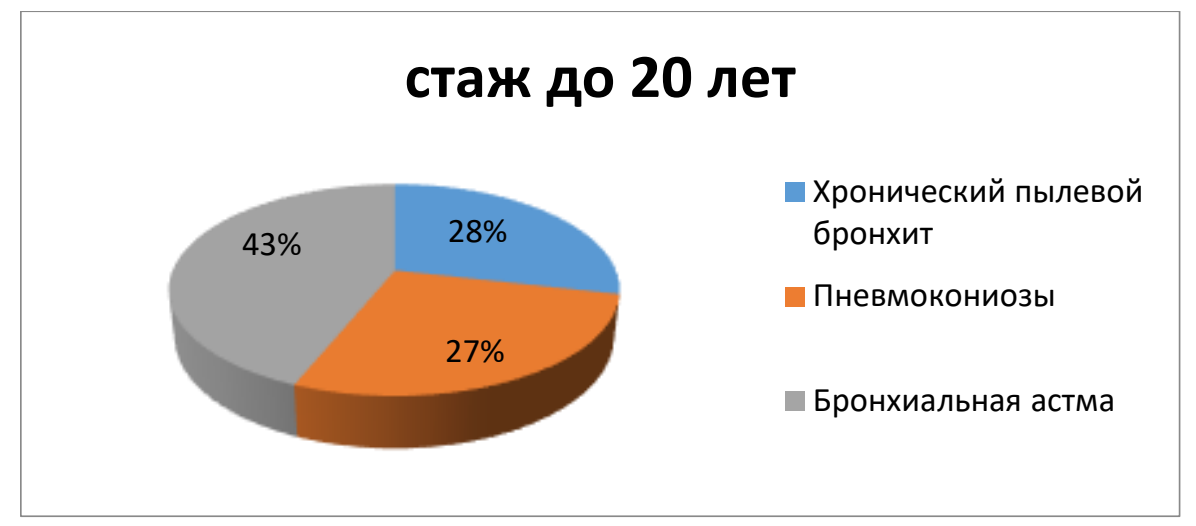

Диаграмма 1. Распределение обследованных в \% со стажем до 20 лет.

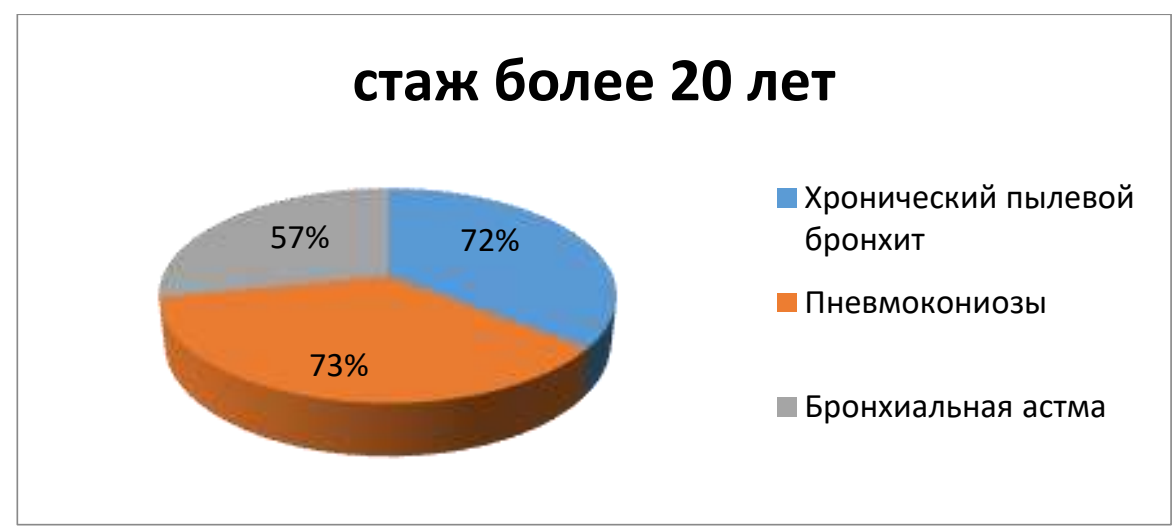

Диаграмма 2. Распределение больных в \% со стажем более 20 лет.

В группе больных с пневмокониозами и с хроническим пылевым бронхитом различий практически не было выявлено, меньше встречались пациенты с бронхиальной астмой. Наиболее часто фенотип А встречался в 1 группе (20 чел.) а во 2 и 3 группе он практически был одинаков 9 и 7 больных, фенотип В во всех группах был приблизительно равен по встречаемости, лишь фенотип АВ отсутствовал у больных с бронхиальной астмой, а у горняков с ХПБ и Пн не отличался по частоте встречаемости.

Таким образом, при увеличении стажа работы (более 20 лет) при неблагоприятных факторах производства достоверно возрастает количество выявленных случаев встречаемости фенотипа $\mathrm{O}$ и А при пылевых бронхитах и пневмокониозах, в отличие от бронхиальной астмы. При бронхиальной астме чаще выявлен фенотип А, чем все другие группы крови, и совсем отсутствовали пациенты с аллоантигеном АВ. При стаже до 20 лет, наоборот, IV группа крови не встречалась ни у больных с хроническим пылевым бронхитом, ни с пневмокониозами.

Результаты проведенного исследования могут свидетельствовать о том, что индивидуальная предрасположенность к действию производственно-экологических и биологических факторов определяется 
генетическими особенностями организма горняков, занятых добычей полиметаллической пыли, которая более патогенная, по сравнению с другими факторами.

Данные особенности с применением скрининговых генетических маркеров позволяют глубже определить механизмы действия полиморфных систем крови. Следует расширить спектр исследований в данном направлении с помощью высоко-технологичных молекулярно-биологических технологий для получения глубокого и точного результата исследований в данном направлении. Можно предположить, что практически каждый ген, детерминирующий аллоантигены тканевых структур, вносит определенный вклад в формировании чувствительности к неблагоприятным производственно-экологическим факторам на уровне клеточных систем.

\section{ЛИТЕРАТУРА:}

1. Бочков Н.П. Экологическая генетика человека //Медицина труда и промышленная экология.-2014.№1.C.1-6.

2. Куляс В.М., Трунова О.А., Мухин В.В., Решетюк В.А. Генетические маркеры крови и иммунологическая реактивность при хроническом пылевом бронхите//Украинский пульмонологический журнал.- 2002.- №3.- С.1821.

3. Куляс В.М., Трунова О.А., Мухин В.В., Решетюк В.А. Иммунно-генетические маркеры риска развития заболеваний органов дыхания//г. Донецк, НИИ медико-экологических проблем Донбасса и угольной промышленности// http://www.health.gov.ua > Publ > conf.nsf > OpenDoc.-2017г.

Сведения об авторах:

1.Чергизова Бибигуль Тулегеновна, ассоциированный профессор кафедры морфологии и физиологии НАО Медицинский университет Караганды, г.Караганда, Казахстан.

2. Шарипова Постумия Анваровна, доцент кафедры физиологии и патофизиологии Ташкентского государственного стоматологического института

3.Атаходжаева Матлуба Абдураимовна, доцент кафедры биохимии Ташкентского государственного стоматологического института

4.Ишигов Ибрагим Агаевич, профессор кафедры морфолггии и физиологии человека Международного Казахско-Турецкого Университета им.Х.А.Ясави

5.Иманова Дайраш Нуржигитовна, доцент кафедры лабораторных дисциплин Международного КазахскоТурецкого Университета им.Х.А.Ясави 